\title{
O PERCURSO DOS ESTUDOS \\ CLÁSSICOS NO BRASIL
}

$$
\text { Zelia de Almeida Cardoso (USP)* }
$$

RESUMO: Este artigo tem o objetivo de explorar o trajeto dos estudos clássicos no Brasil focalizando a educação jesuítica, as academias literárias do século XVIII, a literatura do período arcádico, o papel do teatro na divulgação da cultura clássica, a organização dos programas da educação secundária e, finalmente, a criação das Faculdades de Letras e das sociedades científicas que se ocupam da Antiguidade clássica.

PALAVRAS-CHAVE: educação jesuítica; academias literárias; papel do teatro; educação secundária; sociedades científicas.

\section{THE PATH OF CLASSICAL STUDIES IN BRAZIL}

ABSTRACT: This article aims at exploring the path of classical studies in Brazil with focus on the Jesuit education, the literary academies of the 18th century, the literature of the Arcadian period, the role of theater in the dissemination of classical culture, the organization of secondary education and the creation of Faculties of Letters and scientific societies dedicated to classical antiquity.

KEYWORDS: Jesuit education; literary academies; the role of theater; secondary education; scientific societies

Falar da trajetória dos estudos clássicos no Brasil remete-nos à origem da sistematização da educação brasileira e, por conseguinte, à chegada dos jesuítas à Província de Santa Cruz, na época colonial ${ }^{1}$. Fernando de Azevedo, em A cultura brasileira, discorre detidamente sobre esse momento e afirma:

\author{
* Zelia de Almeida \\ Cardoso é Professora \\ Titular (aposentada) de \\ Língua e Literatura Latina \\ do DLCV- FFLCH-USP, \\ Professora Sênior da USP, \\ Sócia Honorária da SBEC, \\ Membro Honorário da \\ SBR e líder do Grupo de \\ Pesquisa "Estudos sobre \\ o Teatro Antigo" (USP- \\ CNPq). É autora de livros, \\ capítulos de livros e artigos \\ científicos publicados em \\ periódicos. \\ 1. Para organizar nossas \\ reflexôes sobre esse \\ primeiro momento de \\ nossa história, recorremos \\ sobretudo à obra de \\ Fernando de Azevedo, $A$ \\ cultura brasileira, e à de \\ Tito Lívio Ferreira, História \\ da educação lusobrasileira. \\ São textos que, embora \\ publicados há já algum \\ tempo, apresentam um \\ repositório de informações \\ muito bem documentadas \\ que nos possibilitam \\ uma visão abrangente do \\ assunto. V. AzEvedo, F. \\ A cultura brasileira. $4^{\mathrm{a}}$. \\ ed. rev. e ampl. Brasília: \\ Editora Universidade de \\ Brasília, 1963; e FERREIRA, \\ T. L. História da educação \\ lusobrasileira. São Paulo: \\ Saraiva, 1966.
}


2. A primeira missão jesuítica, que integrou a comitiva de Tomé e Souza em sua vinda ao Brasil, era constituída pelos padres Manuel da Nóbrega, Antônio Pires, Leonardo Nunes e João de Azpicuelta Navarro, e pelos irmãos Vicente Rodrigues e Diogo Jácome (Ferreira, 1966, p. 32). Para complementação das informações sobre a permanência dos jesuítas na colônia, veja-se LEITE, S. S. História da Companhia de Jesus no Brasil. Lisboa: Portugalia / Rio de Janeiro:

Civilização Brasileira, 1938.

3. A carta, dirigida por Nóbrega ao Pe. Simão Rodrigues, Superior da Ordem em Lisboa, é de 10 de abril de 1549 e os jesuítas aqui haviam chegado a 29 de março (Ferreira, 1966, p. 26).

$A$ referência às datas se encontra em LeiTe, S. S.

Cartas do Brasil e mais escritos do Padre Manuel da Nóbrega (Opera omnia). Coimbra: 1955. p. 20.

4. Os sete jesuítas que vieram ao Brasil com Duarte da Costa - os padres Luís da Grã, Braz

Lourenço e Ambrosio

Pires e os irmãos José de Anchieta, Antonio Blasques, João Gonçalves e Gregório Serrão

(FERREIRA, 1966, p. 41)

- se somaram aos seis primeiros, que chegaram com a comitiva de Tomé de Sousa, e aos padres Afonso Braz, Francisco Pires, Manoel de Paiva e Salvador Rodrigues que haviam vindo em 1550 (Ferreira, 1966, p. 32).
A vinda dos padres jesuítas, em 1549, não só marca o início da história da educação no Brasil, mas inaugura a primeira fase, a mais longa dessa história, e, certamente, a mais importante pelo vulto da obra realizada e, sobretudo, pelas consequências que dela resultaram para nossa cultura e civilização" (Azevedo, 1963, p. 501).

Comentando a assertiva do sociólogo-educador, poderíamos dizer, a partir da focalização de alguns pontos da educação jesuítica, diretamente relacionados com os estudos clássicos, que as consequências referidas se estendem até hoje.

Os episódios que envolvem esse período de nossa história são bastante conhecidos. A primeira missão jesuítica aqui chegou em 1549, com Tomé de Souza - o Governador Geral então nomeado -, sob o comando de Manuel da Nóbrega, por solicitação expressa de D. João III à Companhia de Jesus, da qual ele havia sido o grande incentivador e o promotor financeiro. A missão tinha o encargo de catequizar os índios e organizar a educação na Província e era composta de padres e irmãos ${ }^{2}$, subvencionados pela Coroa portuguesa. Chegando à Bahia, entregaram-se eles imediatamente à tarefa que lhes fora proposta.

Conforme uma carta de Nóbrega enviada ao Superior da Ordem em Lisboa duas semanas após a sua chegada, e referida por Tito Lívio Ferreira ${ }^{3}$, em História da educação lusobrasileira, o pomposamente denominado Real Colégio da Bahia fora fundado e começara a funcionar doze dias após o estabelecimento dos jesuítas em Salvador e nele o Irmão Vicente Rao, o primeiro mestre-escola a exercer seus ofícios no Brasil, estava ministrando a meninos aulas de "ler e escrever". Em 1552, de acordo com outra carta de Nóbrega, o Pe. Leonardo Nunes, além de ensinar a "ler, escrever e contar", dava lições de "língua portuguesa e até latina”. Foi o início dos estudos clássicos no Estado do Brasil, em um colégio mantido por Portugal.

No ano seguinte, com Duarte da Costa - o novo Governador Geral que substituiu o primeiro -, vieram mais sete jesuítas, unindo-se aos dez que aqui já estavam ${ }^{4}$, contando-se entre eles aquele que seria o grande cultivador das letras clássicas em Santa Cruz, o noviço José de Anchieta.

Muito jovem, com 19 anos de idade, apesar de acometido por problemas de saúde, Anchieta se valeu da sólida for- 
mação humanística recebida em Coimbra e de uma dedicação sem limites à causa jesuítica, tornando-se um eficiente colaborador de Nóbrega em todas as lides daqueles primeiros momentos, tanto em Salvador, como no Espírito Santo e em São Vicente, nos novos estabelecimentos de ensino então criados, e sobretudo em São Paulo, onde desempenhou importante papel na fundação do colégio com o qual se iniciaria um novo aldeamento. Conforme referência encontrada em José González Luis ${ }^{5}$, em José de Anchieta: vida y obra, foi ali que o noviço, durante uma década, exerceu as tarefas de mestre de humanidades, sendo responsável pelas aulas de latim, direcionadas a seminaristas, irmãos e sacerdotes, e pelas de doutrina cristã frequentadas por meninos índios.

Ao mesmo tempo em que se ocupava da vida religiosa, da docência e da catequese, Anchieta se dedicou às letras, compondo, além de textos em prosa, como cartas, relatórios, e sermões, obras poéticas em tupi, português, espanhol e latim, filiadas a diversos gêneros.

E foi em latim que, entre 1560 e 1562, ele escreveu um de seus textos literários mais importantes, o poema épico De gestis Mendi de Saa ${ }^{6}$ (Feitos de Mem de Sá), a primeira epopeia escrita na América, publicada em Portugal em 15637, nove anos antes da publicação de Os Lusíadas.

Precedido por uma epístola ${ }^{8}$, o poema propriamente dito, composto de quase 3.000 versos hexâmetros e dividido em livros ${ }^{9}$, tem por assunto os fatos ocorridos no primeiro triênio do governo de Mem de Sá, iniciado em 1558. Os três primeiros livros são consagrados, sobretudo, a narrativas de embates entre portugueses e índios; no livro 4, o assunto dominante é a conquista e a destruição do forte de Villegaignon, situado na ilha de Serigipe, na baía da Guanabara, construído por franceses que intentavam instalar a França Antártica no Brasil.

Épico, portanto, pelo assunto tratado, De gestis revela profunda influência da epopeia antiga. O livro 1, por exemplo, dedicado todo ele ao relato dos fatos que marcaram a batalha de $\mathrm{Cricar}^{10}$, se inicia, conforme a tradição retórica, por uma invocação - a Cristo Rei e não às Musas - à qual se segue a proposição: cantar o poder de Deus, que se manifestara nas glórias de Mem de Sá. A narração da batalha apresenta a figura de um legítimo herói épico, encarnado na pessoa de
5. Importantes informações sobre José de Anchieta podem ser encontradas em texto editado por Francisco González Luis: LUIS, F. G. (edit.). José de Anchieta: vida y obra. La Laguna (Tenerife): 1988. Nesse livro muitas das informaçōes oferecidas remetem a VIOTTI, H. A., S.J. Anchieta, o Apóstolo do Brasil. São Paulo,

Loyola, 1966.

6. Todas as referências ao poema épico de Anchieta têm por base a edição do Pe. Armando Cardoso: ANCHIETA, Pe. Ioseph de. De gestis Mendi de Saa. Poema epicum. Original acompanhado de introdução, versão e notas pelo Pe. A. CARDOSO, S.J. São Paulo: 1970.

7. Enviado por Mem de Sá a Portugal, o poema foi publicado anonimamente pelo tipógrafo régio João Álvares, mas a análise do poema não deixa dúvidas quanto a sua autoria. Cf. CARDOSO, A.

"Introdução históricoliterária”. In: ANCHIETA, 1970. p. 7-26.

8. A epístola, em dísticos elegíacos, é dirigida a Mem de Sá, a quem o De gestis foi dedicado e não pertence ao corpo do poema, mas, na edição por nós compulsada (ANCHIETA, 1970), seus versos são numerados de 1 a 108 e a epopeia propriamente dita se inicia no verso 109 , estendendo-se até o 3058. Trata-se de uma numeração em sequência, diferente da que é usual nas epopeias clássicas, quando se numeram os versos livro a livro. 
9. Pe. Armando Cardoso, tradutor do texto e autor da "Introdução históricoliterária” que precede a tradução (CARDOSO, 1970, p. 27 ss.), propóe a divisão do poema em quatro livros, sendo o quarto uma subdivisão do terceiro.

10. A batalha de Cricaré, a "prima pugna" no dizer de Anchieta (v. 183-4), ocorreu em 1558 na capitania do Espírito Santo, e assim foi denominada por terse travado às margens do rio Cricaré, hoje São Mateus, tendo por opositores portugueses e indígenas rebelados (tamuya, conforme o poeta - v. 206). No Capítulo VII de sua História do Brasil, concluída em 1627, mas só publicada em 1889, Frei Vicente do Salvador relata as ocorrências dessa batalha, tratando-a de forma sóbria, sem se valer das tintas épicas empregadas por Anchieta. Cf. Frei Vicente do SALVADOR.

Historia do Brasil - 15001567. São Paulo e Rio: Weiszflog Irmãos (Editores proprietários), 1918. p. 167-168.

11. Em linguagem puramente clássica, Anchieta acrescenta à narrativa: Ipsae illum siluae e trupes montesque propinqui, maestaque cum uitreis labentem flumina lymphis/ uulneribus uidere, alto et gemuere dolore (v. 657-9) ("As próprias selvas e rochas e montes vizinhos e rios, / chorando ao som das águas cristalinas, o viram/ cair ao peso das
Fernão de Sá, filho do Governador Geral. Anchieta explora o episódio de maneira realista, descrevendo o cenário, falando das fortificações e trincheiras, dos ornamentos corporais e armas dos selvagens, de sua ferocidade e, principalmente, do heroísmo de Fernão, que, trespassado por flechas, encontrou a "bela morte" na flor da juventude ${ }^{11}$, a exemplo de Niso, Euríalo ou Palante, jovens heróis retratados por Virgílio nos cantos 9 e 10 da Eneida (Aen. 9, 314 ss. e 10, 439 ss.).

Ao lado do aspecto heroico, há um clima de religiosidade percorrendo o poema e se concretizando nas referências a Deus, a Jesus Cristo, ao Espírito Santo e aos anjos; numa lembrança do modelo virgiliano, no entanto, o poeta evoca muitas vezes antigas crenças e se refere às mesmas divindades mitológicas ${ }^{12}$ que se encontram na poesia latina.

A modernidade, porém, se mescla ao antigo no poe$\mathrm{ma}^{13}$. Embora as lembranças clássicas sejam observadas a todo momento, De gestis se reveste de originalidade por ser um texto basicamente cristão, no qual a brasilidade se extravasa nas referências à paisagem, às plantas e aos animais tropicais e na criação de um vocabulário neológico para designar, em latim, tudo aquilo que era típico de uma região tão distante do velho Lácio, no espaço e no tempo ${ }^{14}$.

Além de De gestis, Anchieta compôs em língua latina, odes sáficas, elegias, hinos e epigramas, bem como o De Beata Virgine Dei Matre Maria (Sobre a gloriosa Virgem Maria, Mãe de Deus), um poema em dísticos, também de caráter narrativo, com 5.732 versos e cuja data de composição é controvertida $^{15}$. Nesse texto, Anchieta relatou a vida da Virgem ${ }^{16}$, utilizando como fonte o Novo Testamento, mas revelando alguma influência de Ovídio, nas marcas elegíacas que perpassam o poema, bem como de cânticos medievais que haviam sido compostos em latim ${ }^{17}$.

Com essas obras, Anchieta aliou às funções de preservador e divulgador da cultura clássica, o de ter criado a latinidade literária brasileira ${ }^{18}$.

Durante todo o século XVI as notícias sobre os reais colégios continuaram a chegar aos superiores da Ordem, em Portugal, sob a forma de cartas e relatórios. Em 1564, entre as informações sobre os estudos de Letras Humanas, realizados no Real Colégio da Bahia, constou que o Irmão Luiz Carvalho, que havia chegado no ano anterior, estabelecera em seu 
programa de trabalho didático uma "hora de poesia", lendo em voz alta o livro 2 da Eneida para os alunos mais adiantados (FERREIRA, 1966, p. 69).

Em 1599, com a publicação da Ratio studiorum ${ }^{19}-$ um conjunto de regras pedagógicas a serem observadas em escolas jesuíticas -, conforme um plano de estudos estabelecido para os colégios de Portugal, Angola, Ásia e Brasil, o estudo das humanidades era considerado fundamental e abrangia a gramática e a retórica, devendo ser estudados nesses cursos excertos de autores antigos tais como Homero, Demóstenes, Isócrates, Sófocles, Eurípides, Aristóteles, Cícero, César, Vírgílio, Horácio, Ovídio, Tito Lívio, Sêneca, Tácito, São João Crisóstomo, São Basílio e outros (FERREIRA, 1986, p. 84-87).

Até 1759, quando os jesuítas foram expulsos do Brasil, além de alguns "recolhimentos" femininos, haviam sido por eles criados vinte colégios e doze seminários, instituições essas disseminadas de norte a sul ${ }^{20}$, nelas se dando lugar, ao lado de outras disciplinas tais como as artes, a música e as matemáticas, tanto aos estudos de caráter religioso quanto aos estudos clássicos: a filosofia, a retórica, a gramática, as línguas antigas.

Durante esses duzentos e dez anos em que a educação no Brasil esteve praticamente sob a responsabilidade dos jesuítas, deu-se especial relevo à formação de humanistas, podendo ser citados alguns nomes daqueles que, egressos de colégios e seminários da Ordem, contribuíram de alguma forma para a preservação da cultura clássica. Entre eles lembramos: Bento Teixeira (1561c.-1600), no século XVI, com seu poema épico Prosopopeia, permeado de referências mitológicas ${ }^{21}$; Pe. Antonio Vieira (1608-1697), no século XVII, com sua imensa obra em prosa e seus poemas em latim ${ }^{22}$; Manuel Botelho de Oliveira (1636-1711), com a Música do Parnaso, coletânea "dividida em quatro coros de rimas portuguesas, castelhanas, italianas e latinas", na qual se alinham formas novas, como sonetos e madrigais, permeados, entretanto, de elementos clás$\operatorname{sicos}^{23}$; e Sebastião da Rocha Pita (1660-1738), também ele autor de poemas em português e em latim, obras apresentadas em sessôes ordinárias da Academia Brasílica dos Esquecidos, de que foi um dos fundadores ${ }^{24}$.

De todos esses humanistas, merece uma referência especial o Padre Antonio Vieira, aquele que foi, sem dúvida, o intelectual mais importante do século XVII. Nascido em Lis- chagas, e arrancaram dolorosos gemidos"). As traduçôes do De gestis Mendi de Saa apresentadas no presente texto são da responsabilidade de Armando Cardoso (in ANCHIETA, 1970).

\section{Para referir-se ao} Inferno, por exemplo, Anchieta usa expressões como Tartareae tenebrae (v. 129-30) ("trevas tartáreas"), Erebus (v. 141) ("Érebo"), Stygius (v. 177) ("Estige"), Stygiae lacunae (v. 1165) ("lagoas estígias"), Orcus (558) ("Orco"), Phlegethon (v. 1164) ("Flegetonte"), Plutonia regna (v. 1167) ("reinos de Plutão"); o Céu é frequentemente denominado Olympus (v. 129) (“Olimpo”); o mar é designado pela expressão Tethyos undae (v. 162)

(“águas de Tétis"); a arte da palavra por doctae Mineruae artes (v. 172-3) (“artes da douta Minerva"); os ventos sul e norte pelas denominações latinas Boreas (v. 286; 394), "Bóreas", Notus (404) ("Noto") e Auster (v. 794; 118) (“Austro"); lutas e desforras são indicadas por Mars (v. 721), ("Marte"); a Lua é chamada de formosa Cynthia (753-754) ("a bela Cíntia”), sendo empregado para a designação o epíteto de Diana, identificada com o astro; o vinho é denominado Lyaeus (v. 933) ("Lieu", ou seja,

"Baco"), num duplo emprego de metalepse.

\section{Anchieta não se} restringe apenas à narração de guerras em sua epopeia. Nos livros 2 (810-1731) e 3 (1732-2300), embora os embates entre indígenas 
e portugueses ocorridos em Ilhéus e na região do

Paraguaçu continuem a fornecer-lhe material épico, o poeta reserva espaço para falar das tentativas de pacificação levadas a termo pelo Governador Geral, do estabelecimento de leis que proibiam a antropofagia e as guerras, da substituição das ocas por aldeias, da construção de igrejas e da cristianização das tribos, com vistas ao abandono de antigos costumes dos índios. E aqui ele ressalta em alguns momentos o papel dos jesuítas e dos métodos catequéticos por eles empregados. No livro 4 (2301-3058), porém, o poeta retoma a linha épica ao narrar o episódio da tomada e destruição do forte de Villegaignon.

14. Para maiores esclarecimentos sobre os aspectos literários do De gestis Mendi de Saa, vejase de Armando Cardoso, o capítulo III de sua

"Introdução históricoliterária” à tradução do texto anchietano, intitulado "Qualidades literárias do poema" (ANCHIETA, 1970, 7-79).

15. Conforme uma tradição controvertida e não documentada, o poema teria sido composto em 1563, quando Anchieta, intermediando as negociações entre os portugueses e os indígenas reunidos em Iperuí (hoje Iperoig, Ubatuba), no episódio conhecido como Confederação dos Tamoios, ali permaneceu como refém dos índios enquanto Nóbrega, no boa em 1608, mas residente desde os oito anos no Brasil, onde foi educado no Colégio da Companhia de Jesus da Bahia ${ }^{25}$, Vieira ingressou no seminário aos 15 anos e, aos 18, se tornou o mestre de Retórica do Colégio de Olinda. Depois de ordenar-se, em 1635, revelou-se como pregador, mostrando, conforme Gonçalo Alves, "os prodigiosos dotes de orador que o distinguiam"26. Durante sua existência, dividida entre a vida eclesiástica no Brasil, a permanência em Lisboa, as espinhosas tarefas ditas diplomáticas, na Holanda, França e Roma, Vieira pronunciou cerca de duzentos sermóes, escreveu centenas de cartas e relatórios e compôs poemas em português e em latim.

Os Sermões, sem dúvida a obra mais conhecida de Vieira, ao lado de se configurarem como textos de caráter doutrinário, são também responsáveis pela preservação e divulgação da cultura clássica no Estado do Brasil. Como autênticas peças de oratória compostas por um mestre de Retórica, são notáveis pela composição, pelo estilo, e, sobretudo, pelo conteúdo, revelador tanto da fé cristã do autor como também de seus conhecimentos da história e da cultura greco-romana. Com profunda vivência da língua latina, Vieira inicia cada um dos sermôes com uma epígrafe em latim e os impregna de citações de obras escritas em língua latina ${ }^{27}$. São na maior parte das vezes referências bíblicas extraídas da Vulgata, traduzidas imediatamente para o português a fim de serem compreendidas. O Novo Testamento é a fonte principal das citaçōes ${ }^{28}$, mas Vieira recorre por vezes ao Velho Testamento, citando o Pentateuco, os livros históricos, poéticos, sapienciais e profé$\operatorname{ticos}^{29}$.

$\mathrm{O}$ antigo mundo pagão se faz também presente nas citações de Vieira. No primeiro volume dos Sermōes ${ }^{30}$, encontramos numerosos exemplos de tais citaçôes: há uma referência à Ilíada ${ }^{31}$, quando Vieira evoca a morte de Pátroclo, e a Ulisses, lembrado como fundador de Lisboa ${ }^{32}$; Heráclito é citado em uma menção a Sócrates encontrada no Crátiloo ${ }^{33}$; Platão, a propósito da República; Aristóteles, por seus trabalhos sobre ética ${ }^{34}$; Cícero, por criar oportunidades para reflexōes ${ }^{35}$. Plauto e Terêncio, teatrólogos latinos do período helenístico são curiosamente referidos como autores em cujas comédias se falava de desenganos da vida, da vaidade do mundo e de pontos de doutrina moral ${ }^{36}$. Os escritores latinos da época de Augusto aparecem amiúde nas referências e citações. Vieira 
menciona, principalmente, os poetas. Rememora as profecias de Cassandra, encontradas no livro 2 da Eneida (Aen. 2, 246$247)^{37}$; a tempestade descrita no livro 1 , (Aen. 1, 148-152) (38 $^{38}$ e as palavras de Eneias dirigidas a seu filho Ascânio, no livro 12 (Aen. 12, 435-436) ${ }^{39}$. Relembrando Horácio, considera-o como o maior mestre da retórica e faz citações da Arte Poética $^{40}$. De Ovídio (43 a.C.-17), surpreendentemente, há referências extraídas das Heroides ${ }^{41}$ e transcriçôes de longos trechos das Metamorfoses ${ }^{42}$. Escritores das épocas posteriores também são referidos: de Sêneca, há numerosas citações das Epístolas a Lucílio (Ad Lucilium Epistolae) ${ }^{43}$, da Consolação a Márcia (De consolatione ad Marciam) ${ }^{44}$, de Sobre os benefícios (De beneficiis) ${ }^{45}$, e até mesmo da tragédia Hércules louco (Hercules furens) ${ }^{46}$; há ainda referências tiradas das obras de Lucano $^{47}$ e de Valério Máximo $(14-37)^{48}$.

Dos escritores cristãos dos primeiros tempos - Tertuliano (150?-222?), Ausônio (310-395), Ambrósio (330?-397), Jerônimo (340?-420), Crisóstomo (347-407), Agostinho (354-430), Cassiodoro (490-581) - , que viveram entre os séculos II e VI, há numerosas citações em latim, o que seria de supor-se ${ }^{49}$, o mesmo ocorrendo com alguns autores da Idade Média, tais como Bernardo de Clervaux (1090-1123) ${ }^{50}$ e Tomás de Aquino (1225-1274) ${ }^{51}$.

Concluindo, podemos afirmar que Vieira, como intelectual, foi uma figura ímpar do século XVII, um marco para os estudos clássicos, tanto no plano do ensino como no da divulgação da cultura antiga.

Com a expulsão dos jesuítas, em 1759, a situação do ensino no Brasil sofreu, de início, um profundo colapso. $\mathrm{O}$ que ocorreu, conforme Fernando de Azevedo (1963, p. 539), não foi apenas uma reforma "mas a destruição pura e simples de todo o sistema colonial do ensino jesuítico". Não se tratou simplesmente da substituição de um sistema por outro, mais adequado aos ideais do momento, mas da extinção de uma organização escolar "sem que essa destruição fosse acompanhada de medidas imediatas bastante eficazes para lhe atenuar os efeitos ou reduzir a sua extensão". O ensino jesuítico, tachado de uniforme, dogmático, abstrato, autoritário, excessivamente literário e retórico, foi substituído aos poucos não por escolas condizentes com o espírito enciclopedista e iluminista, com ênfase em disciplinas modernas e científicas, mas, sim, por va-
Rio de Janeiro, ultimava as negociaçôes para obter um compromisso de paz com os indígenas. Fornell Lombardo, entretanto, em "El poema mariano" (LUIS, 1988, p. 245), aventa a possibilidade de alguns cantos do poema terem sido compostos em Coimbra quando Anchieta ai estudava.

16. Mais longo que o De gestis, De beata Virgine é dividido em cantos nos quais são narrados fatos relevantes da vida da Virgem Maria, tais como a encarnação do Verbo, a visitação a Isabel, o nascimento de Jesus, a fuga para o Egito, a paixão e ressurreição de Cristo e a glória de Maria.

17. Ver MINDLIN, D. M. V. "O poema à Virgem de José de Anchieta: uma biografia contemplativa”. In: Itinerários. Araraquara, 2000, n. 15/16, 245-260.

18. Além dos poemas em latim a que nos referimos e de toda uma produção poética em espanhol e português, na qual se destacam os autos compostos especialmente para serem representados por ocasiāo de festividades religiosas, Anchieta compôs quadrinhas em tupi.

\section{A Ratio studiorum é} uma espécie de coletânea de observações pedagógicas, composta com a finalidade de instruir os jesuítas sobre a natureza, a extensão e as obrigações do seu cargo e destinada a unificar os procedimentos pedagógicos, sistematizando a pedagogia jesuítica; 
contém 467 regras referentes às atividades relacionadas com o ensino. Para maiores informações sobre a educação jesuítica veja-se CHARNOT, F. La pédagogie des jésuites. Paris: Spes, 1951.

20. Havia colégios em Salvador, Olinda, Rio de Janeiro, Belém, Amazonas, São Luiz do Maranhão, Alcântara, Fortaleza, Piauí, Paraíba, Recife, Ilhéus, Porto Seguro, Vitória, São Vicente, São Paulo, Santos,

Paranaguá, Desterro (Florianópolis), Colônia do Sacramento, Cachoeira (Bahia), Mariana, Aquirás (Ceará), Giquitaia (Bahia), Itapicuru (Maranhão) e Igaraçu (Pernambuco).

21. Cf. LUNA, Jairo Nogueira. Retórica da Poesia Épica Brasileira: de Bento Teixeira a Sousândrade. Monografia de Mestrado. São Paulo:

USP, 1997; e FELIPE, Cleber Vinicius do Amaral.

"Mitologia e emulação poética em Prosopopéia:

harmonização entre elementos potencialmente conflitantes". In: História \& Perspectivas, 41, 2009

353-382.

22. Veja-se, sobre um exemplo de poema em latim, BORTOLANZA,

J. "Poema novilatino de Vieira: 'Dísticos à abstinência com que Sua Alteza venceu a febre'”. In:

Humanitas 2007, n. 59, 283-292.

23. Cf. OLIVEIRA, Manuel Botelho de; TEIXEIRA, Ivan. Musica do Parnaso (edição fac- gos cursos ministrados principalmente em conventos, as chamadas "aulas régias", subvencionadas pela Coroa portuguesa e espalhadas pelas capitanias. Curiosamente, eram cursos de gramática latina, em sua grande maioria, mas havia também "aulas régias" de grego, hebraico, filosofia (racional e moral), teologia, retórica, poética, ministradas sobretudo por padres e egressos de seminários. Só muito mais tarde, já ao alvorecer do século XIX, é que foram criados cursos de aritmética, geometria, trigonometria, desenho, francês, ciências físicas e naturais.

Não se pode dizer, portanto, que nas quatro últimas décadas do século XVIII, os estudos clássicos tenham sido relegados ao esquecimento. As "aulas régias" os mantiveram, de alguma forma, e as academias literárias, que começaram a funcionar antes mesmo da expulsão dos jesuítas, e das quais participaram intelectuais de formação humanística, foram responsáveis por uma significativa produção literária, em grande parte escrita em latim, que mostrava o conhecimento dos clássicos revelado pelos escritores a elas filiados. A obra de Aderaldo Castello, O Movimento Academicista no Brasil 1641-1820/22 $2^{52}$, e, sobretudo, a criação do Archivum Generale Poetarum Latinorum Brasiliensium, em 1972, por iniciativa de docentes da Faculdade de Filosofia, Ciências e Letras de Assis, hoje integrada à UNESP, foram responsáveis pela recuperação de grande parte do acervo produzido pelas academias. Esse acervo têm sido bastante explorado e já deu origem a numerosas teses de doutorado, monografias de mestrado, artigos publicados em periódicos científicos e livros ${ }^{53}$.

As cinco academias que estiveram em funcionamento no século XVIII, criadas entre 1724 e 1770 - a Academia Brasílica dos Esquecidos, fundada em Salvador, em 1724 e extinta em 1725, a Academia dos Felizes e a Academia dos Seletos, fundadas no Rio de Janeiro em 1736 e 1752, respectivamente; a Academia dos Renascidos, fundada em 1759, na Bahia; a Academia de Letras de São Paulo, em 1770, bem como a Sociedade Literária, criada em 1786, no Rio de Janeiro -, tiveram curta duração e se ocuparam sobretudo de celebrações de efemérides e eventos, mas desempenharam importante papel para a chamada Latinidade Brasileira.

$\mathrm{Na}$ esteira das academias e operando como uma espécie de prolongamento do movimento arcádico português, des- 
ponta em Vila Rica, por volta de 1782, o arcadismo brasileiro com figuras tais como Cláudio Manuel da Costa (17291789), Inácio José de Alvarenga Peixoto (1742/44-1792/93), Tomás Antônio Gonzaga (1744-1810) e Manuel Inácio da Silva Alvarenga (1749-1814), poetas imbuídos do espírito da época que, além da produção poética desempenharam importante papel nas atividades políticas do momento. Como árcades, foram responsáveis por uma poesia que se voltava para o mundo antigo, especialmente para o bucolismo e o lirismo, mas se valeram de elementos modernos para ressuscitar o classicismo.

Não se pode desprezar, também, a função desempenhada pelo teatro, no século XVIII, como elemento divulgador e popularizador de temas clássicos, por meio de peças e óperas que focalizavam lendas míticas e fatos históricos da Antiguidade e que se alternavam com outras que exploravam temas diversos. Leve-se em conta o fato de ser o teatro no século XVIII uma das poucas formas de entretenimento cultural coletivo e de serem as comédias, entremezes, cantatas, pastorais e, principalmente, as óperas, muitíssimo apreciadas pelo público. De origem italiana, sobretudo, aclimataram-se estas no mundo lusófono, foram traduzidas e adaptadas e trouxeram a uma audiência, não raro deslumbrada, histórias cômicas e trágicas, entre as quais estavam aquelas que exploravam aspectos do mundo antigo. Sobre elas nos deteremos. A documentação que temos é precária, mas do que restou em arquivos especiais podemos verificar que em Salvador, Vila Rica, Rio de Janeiro, São Paulo, e em muitas outras cidades brasileiras, houve numerosas representações de peças teatrais e óperas que revelaram a velha cultura.

Uma das informações mais antigas que temos sobre representações dramáticas de assunto relacionado com a Antiguidade, no Brasil, vem de Salvador e é de $1729^{54}$. Encontra-se em relatório oficial ${ }^{55}$ e se refere a comemorações ocorridas na Bahia como "Ação de Graças" pelo casamento dos "Sereníssimos Príncipes de Portugal e de Castela". Entre as celebrações houve a encenação de seis espetáculos teatrais em um tablado equipadíssimo, montado na cidade, na Praça de Palácio ${ }^{56}$. Dois desses espetáculos trouxeram reminiscências do mundo clássico ao público presente: a zarzuela mitológica Los juegos olympicos, uma das principais obras do dramaturgo espanhol similar); São Paulo: Ateliê Editorial, 2006.

24. Para maiores informaçōes, veja-se: PINTO, N. P. A poesia de Rocha Pita na Academia Brasílica dos Esquecidos. Vol. II, Anexo. Belo Horizonte: Faculdade de Letras da UFMG, 2007.

Endereço eletrônico: http:// www.bibliotecadigital. ufmg.br/dspace/bitstream/ handle/1843/ECAP-

6Z8E87/anexo_poesia. pdf? sequence $=2$

25. Segundo Pe. Gonçalo Alves, responsável por uma reedição completa dos Sermốes, e autor do prefácio da obra, foi no Colégio da Companhia de Jesus da Bahia que Vieira iniciou seus estudos literários, "revelando logo tão singular agudeza de engenho e tão clara inteligência que os padres, prevendo o seu extraordinário talento, procuraram atraí-lo a seu grêmio". Cf. VIEIRA, A. Sermóes. Prefaciado e revisto pelo Revmo. Pe. G. ALVES. Porto: Lello \& Irmão. Edit. 1959. p. XXXIV. A obra, com a totalidade dos sermões, se compóe de cinco volumes, cada um dos quais dividido em três tomos.

26. De acordo com Gonçalo Alves (VIEIRA, 1959, p. XXXIV-XXXV), foi nessa época que Vieira escreveu comentários a obras de Sêneca e Ovídio, textos que não chegaram até nós.

27. Ver SANTANA, M. A. A importância do latim em Vieira. In: CELLI 
- Colóquio de Estudos

Linguísticos e Literários. 3, 2007, Maringá. Anais... Maringá, 2009, p. 1800-

1807.

28. Vieira em numerosos momentos se vale de trechos dos Evangelhos, dos Atos dos Apóstolos, das epístolas e do Apocalipse.

29. Há citaçôes dos livros de Josué, dos Juízes, dos Reis; dos Salmos e do Cântico dos Cânticos; do livro de Jó, dos Provérbios,

do Eclesiastes, do livro

da Sabedoria; dos livros de Isaías, Jeremias,

Daniel, Oseias, Zacarias,

Malaquias, Habacuc, Amós e Joel.

30. Ver ed. citada. O Vol. I. é dividido em três tomos

(I. II e III), cada um com numeração própria de páginas.

31. VIEIRA, 1959, Vol.

I, t. I, p. 24. "Sermão da Sexagésima” VII: "As armas alheias”, diz Vieira, referindo-se ao herói grego que se valera das do amigo,

"ainda que sejam as de Aquiles a ninguém deram vitória”.

32. Idem, p. 213. "Sermão da Terceira Dominga de Advento", VII: Vieira se vale de informaçōes sobre Olisipo, transmitidas por Plínio e Varrão.

33. Idem, p. 127. "Sermão da Primeira Dominga de Advento", V (1652): Vieira se refere ao conhecido aforismo de Heráclito, Non posse quemquam bis in eumdem fluvium descendere ("Ninguém
Agustín de Salazar y Torres, e a comédia musical El monstruo en los jardines, de Calderón de la Barca, na qual Netuno, Ceres, Vênus, Apolo e Amor compareciam como personagens e eram acompanhados por dois coros.

Em 1760, agora em comemoração ao casamento de D. Maria, futura rainha de Portugal, com seu tio D. Pedro, no Teatro de Ópera, então construído para substituir o anterior, foram representadas três das chamadas "óperas sérias" de Pietro Metastásio ${ }^{57}$ : duas com assuntos baseados na história antiga, Alexandre na Índia ${ }^{58}$ e Artaxerxes ${ }^{59}$, e uma inspirada na Eneida de Virgílio, Dido abandonada ${ }^{60}$. Na mesma ocasião, nas proximidades de Salvador, na Vila de Nossa Senhora da Purificação e Santo Amaro ${ }^{61}$, houve também festejos em honra do mesmo casamento real, tendo sido então representada a "ópera da fábula de Anfitrião" 62 . Trata-se possivelmente de Anfitrião ou Júpiter e Alcmena, de Antônio José da Silva, o Judeu $^{63}$, o mais famoso teatrólogo lusófono do século XVIII.

As óperas de Metastásio, musicadas por numerosos compositores, e as "obras joco-sérias" de Antônio José, algumas das quais com música de Antônio Teixeira, foram representadas muitas vezes, no século XVIII, nos principais centros urbanos da Província.

Em Vila Rica, hoje Ouro Preto, dada a sua importância econômica e cultural na época, houve representações de entremezes e comédias desde 1728, mas somente em 1751, por ocasião da aclamação de D. José I, é que se tem notícia da representação de duas óperas de tema clássico: Encantos de Medeia e O labirinto de Creta, ambas de Antonio José da Silva (BUDASZ, 2008. p.187). Em 1768, levou-se à cena $\mathrm{O}$ Parnaso obsequioso, alegoria musical de Cláudio Manuel da Costa, peça de caráter encomiástico ${ }^{64}$, que conta com Apolo e Mercúrio como personagens e tem um coro de Musas ${ }^{65}$. Após a inauguração da Casa de Ópera de Vila Rica ${ }^{66}$, em 1769, entre as dezenas de representações que ali se realizaram até o final do século XVIII, estão a zarzuela Jogos olímpicos, em 1971 e, no mesmo ano, além de outras peças de tema clássico ${ }^{67}$, as óperas Coriolano em Roma ${ }^{68}$, de Attilio Ariosti, e Alexandre na Índia, de Pietro Metastásio. Em 1797, foi levada à cena a ópera Ezio em Roma ${ }^{69}$, também de Metastásio, e, em 1798, Alarico em Roma ${ }^{70}$, de Agostino Steffani. 
No Arraial do Tijuco, hoje Diamantina, local que como Vila Rica, se tornou famoso pela mineração, houve representações das óperas Encantos de Medeia e Anfitrião ou Júpiter e Alcmena, de Antonio José da Silva, entre 1753 e 1771, no teatro de Chica da Silva, situado no palácio do famoso contratador de diamantes João Fernandes (BUDASZ, 2008, p. 187).

No Rio de Janeiro, a partir de 1765 foram apresentados diversos espetáculos teatrais relacionados com a Antiguidade. Segundo depoimento de James Forbes, que ali esteve nesse ano, havia na cidade uma "casa de ópera" ${ }^{\text {" na }}$ naul se representavam peças duas vezes por semana; foi ali que o Príncipe Charles-Othon de Nassau-Siegen assistiu à "ópera séria" Coriolano. No mesmo ano de 1765, por meio de um documento redigido por um escrevente, sabemos que o Morgado de Mateus, Governador de São Paulo, estivera na cidade e assistira a cinco óperas cujos assuntos abordavam temas clássicos: Alexandre na India, Dido abandonada, Adriano na Síria e Ciro reconhecido, óperas de Metastásio, e Precipicio de Faetonte, de Antonio José da Silva ${ }^{72}$. A ópera Adriano na Síria foi reapresentada muitas vezes nesse ano. Em 1769 levou-se à cena Os encantos de Medeia, na Ópera Velha e, ao que parece, foi durante essa representação que se incendiou o pequeno teatro, cujo proprietário era o lendário Padre Ventura. Entre 1778 e 1790, já na Ópera Nova, foram representadas, também de autoria de Antonio José da Silva, as óperas Labirinto de Creta, Variedades de Proteu e Precipício de Faetonte.

Em São Paulo, em 1767, ao ser inaugurado um pequeno teatro que funcionava em uma das salas do Colégio São Bento, conforme Budasz (2008, p. 48), ali foi representado em várias récitas, o Anfitriāo, de Antônio José; após a inauguração da Casa da Ópera, muitas outras récitas dessa mesma ópera, bem como de Os encantos de Medeia, foram oferecidas ao público. Em 1770, levou-se à cena Coriolano em Roma e Demofoonte em Trácia ${ }^{73}$ e, em 1771, além de Coriolano, em nova récita, e de Jogos Olímpicos, foram apresentadas as óperas Alexandre na India e A clemência de Tito ${ }^{74}$, de Metastásio.

Até mesmo em cidades mais distantes, como Cuiabá ${ }^{75}$, Belém $^{76}$, Mazagão ${ }^{77}$, São Luís ${ }^{78}$, Recife ${ }^{79}$, houve apresentação de óperas relacionadas com o mundo antigo durante o período em análise. pode entrar duas vezes no mesmo rio").

34. Idem, p. 108. "Sermão da Primeira Dominga de Advento", VII: Vieira comenta um ensinamento de Aristóteles ("Nenhum sábio deve procurar, nem desejar maior certeza, que a que pode ter a matéria que trata”).

35. Idem, p. 115-120.

"Sermão da Primeira

Dominga de Advento", VII: Ao referir-se a Cícero que falou sobre Xerxes, Vieira amplia o assunto, tomando-o como ponto de partida para discorrer sobre guerras e generais da época antiga, bem como para rememorar o sentido da cultura clássica e de seus expoentes nas artes, ciências, filosofia e teologia, o papel dos jogos, as fábulas e os mitos antigos e até para falar das sete maravilhas e das grandes cidades que assombraram o mundo antigo mas muitas vezes se reduziram a ruínas. Idem, p. 33. "Sermão da Sexagésima” IX.

36. Idem, p. 33. "Sermão da Sexagésima” IX.

37. Idem, t. II, p. 71.

"Sermão de Dia de Reis". A rememoração ocorre quando Vieira compara os fados de Pernambuco, ameaçado de destruição pelos hereges, aos de Troia e de Sodoma, evocando a Eneida, de Virgílio, e o Pentateuco.

38. Idem, p. 145. "Sermão das Quarenta Horas”, III: A descrição da tempestade é inserida no sermão para exemplificar 
as consequências das dissensôes entre os homens.

39. Idem, t. III, p. 257.

"Sermão da Terceira

Quarta-Feira da

Quaresma”, III (1669).

Dirigindo-se ao filho, o

troiano póe em paralelo o

papel do valor e a sorte e

o aconselha: Disce, puer,

virtutem ex me verumque

laborem/ Fotunam ex

aliis - Aen. 12, 435-

436 ("Aprende comigo,

meu filho, a virtude e o

verdadeira labor; a sorte

com os outros"). Vieira

se aproveita de partes dos

versos: Virtutem ex me,

Fortunam ex aliis.

40. Idem, t. I, p. 285

e 291. "Sermão do

Nascimento do Menino

Deus”, III e V. Nessas

páginas, respectivamente,

são citados preceitos de

Horácio; na primeira há

uma referência à questão

do utile/dulce: "para

deleitar ensinando se há-

de misturar o útil com

o doce" (Qui miscuit utile dulci lectorem

delectando, pariterque movendo) (HOR. Epist.

2,3,343-344); na segunda, à questão do poder persuasivo daquilo que se vê: e "o que entra pelos ouvidos, como tem menos

evidência, move com menos força; mas o que entra pelos olhos, recebe a eficácia da mesma vista e move fortissimamente (Segnius irritant animos demissa per aures, / quam quae sunt oculis subjecta fidelibus) (HOR. Epist.

2,3,180-181) (Traduções de TRINGALI, 1993).

41. Idem, p. 120. "Sermão da Primeira Dominga de
E assim chegamos ao fim do século XVIII. Para coroá-lo, temos um fato novo que vai exercer profunda influência sobre a educação dos jovens, no século XIX: a criação do seminário de Olinda em 1798, por D. Azeredo Coutinho, bispo de Pernambuco. Egresso da Universidade de Coimbra, reformada e modernizada por Pombal, o prelado concebeu o Seminário, que só realmente começaria a funcionar em 1800, como uma instituição de ensino que atenderia às necessidades do momento, enfatizando o moderno, as ciências, as línguas estrangeiras, mas sem deixar de lado o ensino clássico e as disciplinas humanísticas que se uniram, pois, intimamente, ao ensino científico. Sobre tal instituição, assim se expressa Fernando de Azevedo:

As novas tendências pedagógicas exprimem-se não só no ambiente liberal que nele se criou, com métodos mais suaves e mais humanos, no respeito maior à personalidade do menino, nas transformações profundas das relações dos adultos com as crianças, dos mestres com os discípulos, mas ainda pela importância dada, no plano dos estudos, ao ensino das matemáticas e das ciências naturais. Ao lado das matérias que constituíam o currículo tradicional - a gramática, o latim, a retórica, a poética, a filosofia (mas já segundo novos pontos de vista) e a teologia -, figuram o grego, o francês, a história, a cronologia, a geometria, a física, a história natural e o desenho que se lecionavam não somente aos que queriam fazer o seu curso de humanidades, mas ainda aos que se destinavam às ordens sacras (AZEVEDO, 1966, p. 558).

De início, o Seminário de Olinda foi apenas um caso isolado, mas alguns anos depois, com a vinda da família real para o Brasil, e a consequente independência do País, a educação dos adolescentes tendeu a organizar-se. A criação do Colégio Pedro II, em 1837, cujo currículo, na trilha do Seminário de Olinda, mesclava disciplinas científicas com as de caráter humanístico, foi o ponto de partida para a criação de inúmeros estabelecimentos de ensino nos mesmos moldes, confessionais e leigos, que se espalharam de norte a sul, pelo país, consolidando, de certa forma, o que viria a ser a educação dita secundária, alvo de numerosas leis orgânicas e de diretrizes e bases que se estenderam pelos tempos. Os currículos escola- 
res, uniformes segundo as leis, para garantir a equiparação e o reconhecimento dos estabelecimentos, mantiveram até 1961 disciplinas que corresponderam à permanência dos estudos clássicos em nível dos então primeiro e segundo graus da escola secundária. E os próprios seminários, responsáveis em grande parte pela manutenção de conhecimentos humanísticos e pela ênfase dada aos estudos de latim, adequaram seus currículos aos oficiais.

A partir dos anos 30 do século XX, as Faculdades de Filosofia, Ciências e Letras começaram a surgir, atribuindo aos formados o grau de bacharel, antes concedido pelo Colégio Pedro II. Os cursos de Letras Clássicas proliferaram, garantindo a seus alunos conhecimentos aprofundados de Língua e Literatura Latina, Língua e Literatura Grega, Filologia, Glotologia; outros cursos, como os de Filosofia, História e Ciências Sociais programaram disciplinas em parte voltadas para a Antiguidade, tais como Filosofia, História Antiga, Arqueologia e Antropologia.

Em São Paulo, em 1954, quando os cursos de Letras Clássicas eram ministrados nas quatro Faculdades de Filosofia então existentes ${ }^{80}$, foi criada a primeira Associação de Estudos Clássicos do Brasil, por iniciativa do Prof. Dr. Robert Henri Aubreton, que dois anos antes havia sido contratado pela USP para reger a cadeira de Língua e Literatura Grega ${ }^{81}$.

Congregando classicistas de diversas unidades universitárias do país, a Associação de Estudos Clássicos se desenvolveu rapidamente, passando a contar com Secções em Bauru, Assis, Ceres, Rio de Janeiro, Belo Horizonte, Porto Alegre e outras cidades. Nas reuniões mensais abertas a estudiosos em geral, discutiam-se temas específicos e pronunciavam-se conferências cujos textos eram publicados no Boletim de Estudos Clássicos, periódico bienal mantido pela Associação. Filiada à Fédération Internationale des Études Classiques, a Associação de Estudos Clássicos representou por várias vezes o Brasil em assembléias da Federação, no exterior. Com o retorno do Professor Aubreton à França, entretanto, em meados dos anos 60 , e dado o período de instabilidade política do país, com os problemas que afetaram a vida das universidades e agremiações, a Associação de Estudos Clássicos foi extinta, como tantas outras.
Advento", III. Em uma alusão à ruína das cidades Vieira reproduz parte de um verso de Ovídio contido nas Heroides: Iam seges est ubi Troia fuit $(\mathrm{Ov}$ Her. 1,1,53) ("Agora onde estava Troia há campos cultivados).

42. Idem, p. 121 e 122.

"Sermão da Primeira

Dominga de Advento",

III e IV. Referindo-se a

Ovídio, e considerando-o

como "o mais engenhoso

de todos os poetas",

Vieira cita dois trechos

das Metamorfoses, onde o poeta se refere ao tempo:

o primeiro está contido na

famosa descrição do palácio do Sol (Met. 2,25-30); o segundo no último livro, no trecho em que Ovídio fala de Pitágoras (Met. 15,179-181).

43. Idem, p. 124. "Sermão da Primeira Dominga de Advento", III e IV: Vieira se refere à Epístola 91,7; t. II, p. 193, à Epístola 32; idem p. 239, à Epístola 115.

44. Idem, t. II, p. 187.

"Sermão da Quarta-Feira de Cinza”, VIII (1672).

Vieira se refere à ambição humana que causa cegueira aos homens e exclama: Morimur ut mortales, vivimus ut immortales (SEN. Cons. Marc.)

("Morremos como mortais que somos; vivemos como se fôramos imortais") (Tradução do próprio orador).

45. Idem, t. III, p. 45.

"Sermão da Primeira Dominga de Advento" VII (1653): referência a Ben. 7, 23; p. 254 . "Sermão da Terceira Quarta-Feira 
da Quaresma”, III (1669): referência a Ben. 4, 1.

46. Idem, t. II, p. 234. "Sermão da Quarta-Feira de Cinza”, VIII. Vieira reproduz trecho da fala do tirano Lico, dirigindo-se a Anfitriāo: Miserum veta perire felicem iube - SEN. HF 513 ("Ao feliz ordena que pereça, ao infeliz que viva”).

47. Idem, t. II, p. 204. "Sermão da Quarta-Feira de Cinza”, VIII (1672):

a citação, extraída da Farsália (Pharsalia), ocorre a pretexto do que teria dito

Catão a respeito de sua própria morte (LUc. Phars. 9, 582-583)

48. Idem, p. 240. "Sermão da Quarta-Feira de Cinza”, VI: Vieira reproduz uma assertiva de Valério

Máximo, historiador e geógrafo da época de

Tibério, encontrada em Valeri Maximi factorvm et dictorvm memorabilivm liber vii: Volubilis fortunae conplura exempla retulimus, constanter propitiae admodum pauca narrari possunt - VAL.

MAX. 7. 1 ("Recolhemos numerosos exemplos da instabilidade da sorte, mas sobre seu constante favorecimento poucos podem ser relatados").

49. Veja-se, p.e., VIEIRA, 1959, t. II, p. 156; 192; t.

I, p. 127; t. II, p. 67; 81; 81; 142; 194; t. I, p. 77; t. II, p. 171; t. III, p. 250; t. II, p. 67; 69; 71;78; 90; 92; 155; t. I, p. 155; t. II, p. $89 ; 95 ; 179 ; 199 ;$ t. III, 154; t. II, p. 65.
Em 1971, com a nova regulamentação dos cursos de pós-graduação que já vinham sendo ministrados no país, desde algum tempo, a USP e a UFRJ criaram Programas em Letras Clássicas, não só regularizando a situação daqueles que já tinham condições de titular-se, como permitindo o acesso de novos alunos que se candidatavam a cursos de mestrado e doutorado. Foi um reinício de atividades que permitiu o panorama que hoje se observa: centenas de titulados, cujo número aumenta a cada ano, se espalham pelo país. Outras unidades universitárias, embora não mantivessem Programas específicos, abriram espaço para estudos clássicos em seus Programas de Linguística, Teoria Literária, Filosofia, História; outras ainda, com o correr do tempo, instituíram Programas semelhantes aos pioneiros.

E foi como consequência do que se fazia em nível de pós-graduação, em meados dos anos 80 , quando o país começava a respirar novos ares, que se realizou em Belo Horizonte, sob os auspícios da UFMG, o Primeiro Congresso Nacional de Estudos Clássicos, durante o qual nasceu a ideia da constituição da Sociedade Brasileira de Estudos Clássicos, a SBEC.

O desenvolvimento da Pós-Graduação, em numerosas unidades universitárias, e a instituição da SBEC permitiram o que hoje se constata: a existência de dezenas de grupos de pesquisa, de trabalho e de estudos relacionados com a Antiguidade, a defesa anual de numerosas teses e monografias, a realização de eventos regulares voltados para os estudos clássicos, como congressos, seminários, colóquios e jornadas, a publicação de livros e periódicos científicos, o intercâmbio profícuo de experiências e informações.

E o teatro, que se desenvolveu sobremaneira na segunda metade do século XX, também se constituiu em valioso meio para a divulgação dos antigos textos clássicos, em traduções, adaptações, recriações e atualizações (CARDOSO, $2011 \mathrm{~B}$, p. 31 ss.). É um panorama bastante promissor, portanto, o dos estudos clássicos no Brasil.

\section{REFERÊNCIAS BIBLIOGRÁFICASS}

ABALADA, V. E. T. M. Metastasio por Francisco Luiz Ameno: ópera, poder e literatura nas reformas do Portugal setecentista. Monografia de Mestrado. Rio de Janeiro: Unirio, 2011. 
ALVES, Pe. G. "Padre Antônio Vieira - sua vida". In: VIEIRA, Pe. Antônio. Sermões. Prefaciado e revisto pelo Revmo. Padre Gonçalo Alves. Porto: Lello \& Irmão. Edit. 1959. p. XXXIII-LVI.

ANCHIETA, Pe. Ioseph de. De gestis Mendi de Saa. Poema epicum. Obras completas. $1^{\circ}$. volume. Original acompanhado de introdução, versão e notas pelo Pe. Armando CARDOSO, S.J. São Paulo: 1970.

AZEVEDO, F. A cultura brasileira. 4a . ed. rev. e ampl. Brasília: Editora Universidade de Brasília, 1963.

BORTOLANZA, João. "Poema novilatino de Vieira: 'Dísticos à abstinência com que Sua Alteza venceu a febre”". In: Humanitas 2007, n. 59, 283-292

BRESCIA, Rosana; LINO, Sulamita. “O teatro de tradição ibérica na América Portuguesa na primeira metade do século XVIII: arquitectura e repertório”. European Review of Artistic Studies 2013, vol. 4, n. 1, 31- 53.

BUDASZ, Rogério. Teatro e música na América Portuguesa. Convenções, repertório, raça, gênero e poder. Curitiba: DeArtes-UFPR, 2008

CÂNDIDO, Antonio; CASTELLO, Aderaldo. Presença da Literatura Brasileira I. São Paulo: Difusão Européia do Livro, 1968.

CARDOSO, Armando. "Introdução histórico-literária". In ANCHIETA, Pe. Ioseph de. De gestis Mendi de Saa. Poema epicum. Original acompanhado de introdução, versão e notas pelo Pe. Armando Cardoso, S.J. São Paulo: 1970. p. 7-79.

CARDOSO, Lino de Almeida. O som social. São Paulo: Ed. do Autor, 2011 [A].

CARDOSO, Zelia de Almeida. "O percurso do teatro clássico: da Antiguidade a nossos dias". In: VIEIRA, Brunno V. G. e THAMOS, Márcio (Orgs.). Permanência clássica. Visões contemporâneas da Antiguidade greco-romana. São Paulo: Escrituras, 2011 [B]. p. 13-49.

CASTELLO, José Aderaldo. O Movimento Academicista no Brasil 1641-1820/22. São Paulo: Conselho Estadual de Cultura, 1974.

CASTILHO, Ataliba Teixeira de. "Robert Henri Aubreton". In: Alfa Revista de Linguística. UNESP, 1963, v. 4, 133-137.
50. Idem, t. II, p. 222.

"Sermão da Quarta-Feira de Cinza”, VII. Vieira cita um comentário de São Bernardo a uma frase de são Paulo: Vivo autem jam non ego ("Eu vivo mas já não sou eu”).

51. Idem, t. I, p. 107.

"Sermão da Primeira Dominga de Advento", V (1652): Vieira compara

Santo Tomás com

Aristóteles.

52. CASTELLO, J. A. O Movimento Academicista no Brasil 1641-1820/22.

São Paulo: Conselho

Estadual de Cultura, 1974.

53. Cf. FONDA, E. A; RODRIGUES, M. R. e BINATO, C. V. P. “O estado atual do acervo dos manuscritos junto ao Archivum Generale Poetarum Latinorum Brasiliensium”. In: Patrimônio e Memória. UNESP-FCLAs-CEDAP, 2007, v.3, n.1, 186-194.

54. Cf. BRESCIA, R.; LINO, S. "O teatro de tradição ibérica na América Portuguesa na primeira metade do século XVIII: arquitectura e repertório". European Review of Artistic Studies 2013, vol. 4, n. 1, 31-53. p. 38. Para a cronologia dos espetáculos adiante referidos, ver BUDASZ, R. Teatro e música na América Portuguesa. Convençôes, repertório, raça, gênero e poder. Curitiba: DeArtesUFPR, 2008. p. 187-199.

55. Confira-se o Diário Histórico das Celebridades que na Cidade da Bahia se Fizeram em 
Ação de Graças pelos felicícíssimos casamentos dos Sereníssimos Príncipes de Portugal e Castela, da autoria de Joseph Ferreyra de Matos, publicado em

Lisboa, em 1729. Os casamentos referidos são da Princesa Maria Bárbara

Xavier Leonor Teresa Antónia Josefa, filha de D. João V, de Portugal, com D. Ferdinando, príncipe das Astúrias, que subiu ao trono de Espanha como Ferdinando VI, e de D.

José, de Portugal, com

D. Mariana Victória, de Bourbon. Cf. MAGALDI, Sábato. Panorama do teatro brasileiro. Brasília: MEC/ DAC/ FUNARTE/ Serviço Nacional de Teatro, [1962] p. 27.

56. Para maiores informaçōes sobre tais espetáculos, veja-se BUDASZ, 2008, p. 65 ss.

57. Pietro Metastasio é o pseudônimo de Pietro Antonio Domenico Bonaventura Trapassi (1698-1782), poeta, dramaturgo e libretista, considerado como o reformador do melodrama italiano, ao valorizar o conteúdo histórico e filosófico dos textos operísticos e não apenas a música e a execução.

Os libretos de Metastasio foram musicados por numerosos compositores e traduzidos em várias línguas. Em Portugal o principal tradutor de suas obras foi Francisco Luiz Ameno. Para maiores informações, veja-se ABALADA, Victor Emmanuel Teixeira Mendes. Metastasio por Francisco Luiz Ameno:
CHARNOT, F. La pédagogie des jésuites. Paris: Spes, 1951. ESTEVES, Suely Maria Pierucci. A Ópera de Demofoonte em Trácia: tradução e adaptação de Demofoonte, de Metastasio, atribuídas a Cláudio Manuel da Costa, Glauceste Satúrnio. Monografia de Mestrado. São Paulo: USP, 2007.

FELIPE, C.V.A. "Mitologia e emulação poética em Prosopopéia: harmonização entre elementos potencialmente conflitantes". In: História \& Perspectivas, 2009, n. 41, 353-382.

FERREIRA, T. L. História da educação lusobrasileira. São Paulo: Saraiva, 1966.

FONDA, Enio Aloísio; RODRIGUES, Mirtes Rocha e BINATO, Cláudia Valéria Penavel. "O estado atual do acervo dos manuscritos junto ao Archivum Generale Poetarum Latinorum Brasiliensium”. In: Patrimônio e Memória. UNESPFCLAs-CEDAP, v.3, n.1, 2007 p. 186-194.

LEITE, Serafim Soares. Cartas do Brasil e mais escritos do Padre Manuel da Nóbrega (Opera omnia). Coimbra: 1955. História da Companhia de Jesus no Brasil. Lisboa: Portugalia / Rio de Janeiro: Civilização Brasileira, 1938.

LOMBARDO, J. M. Fornell. "El poema mariano". In: LUIS, Francisco González (edit.). José de Anchieta: vida y obra. La Laguna (Tenerife): 1988. p. 233-249.

LUIS, Francisco González (edit.). José de Anchieta: vida y obra. La Laguna (Tenerife): 1988.

LUNA, Jairo Nogueira. Retórica da Poesia Épica Brasileira: de Bento Teixeira a Sousândrade. Monografia de Mestrado. São Paulo: USP, 1997.

MAGALDI, Sábato. Panorama do teatro brasileiro. Brasília: MEC/DAC/FUNARTE/ Serviço Nacional de Teatro, [1962]. MENDONÇA, Antonio Manuel de Melo Castro e. "Memória econômica política da capitania de São Paulo". In: Anais do Museu Paulista. t. 15, p. 83-247.

MINDLIN, Dulce Maria Viana. "O poema à Virgem de José de Anchieta: uma biografia contemplativa”. In: Itinerários. Araraquara, 2000, n. 15/16, 245-260.

OLIVEIRA, Manuel Botelho de; TEIXEIRA, Ivan. Musica do Parnaso (edição fac-similar). São Paulo: Ateliê Editorial, 2006. 
PÁSCOA, Márcio. "Ópera na Amazônia durante o século XVIII”. In: Música em perspectiva. v. 1, n. 1. março 2008, p. 43-57.

PASQUALE, D.. Metastasio al gusto portoghese: Traduzioni e adattamenti del melodramma metastasiano nel Portogalo del Settecento. Roma: Aracne, 2007.

PINTO, Nilton de Paiva. A poesia de Rocha Pita na Academia Brasílica dos Esquecidos. Vol. II, Anexo. Belo Horizonte: Faculdade de Letras da UFMG, 2007. Endereço eletrônico: http://www.bibliotecadigital.ufmg.br/dspace/bitstream/handle/1843/ECAP-6Z8E87/anexo_poesia.pdf?sequence $=2$

SALVADOR, Frei Vicente do. Historia do Brasil - 15001567. São Paulo e Rio: Weiszflog Irmãos (Editores proprietários), 1918.

SANTANA, Mariana Alves de. A importância do latim em Vieira. In: CELLI - Colóquio de Estudos Linguísticos e Literários. 3, 2007, Maringá. Anais... Maringá, 2009, p. 18001807.

SILVEIRA, Francisco Maciel. Concerto barroco às óperas do Judeu. São Paulo: Perspectiva / EDUSP, 1992.

TRINGALI, Dante. A Arte Poética de Horácio. São Paulo: Musa Editora, 1993.

VIEIRA, Pe. Antônio. Sermões. Prefaciado e revisto pelo Revmo. Padre Gonçalo Alves. Porto: Lello \& Irmão. Edit. 1959. VIEIRA, Brunno V. G. e THAMOS, Márcio (Orgs.). Permanência clássica. Visões contemporâneas da Antiguidade greco-romana. São Paulo: Escrituras, 2011.

VIOTTI, Hélio Abranches, S.J. Anchieta, o Apóstolo do Brasil. São Paulo, Loyola, 1966.

Recebido em novembro de 2013

Aprovado em dezembro de 2013 ópera, poder e literatura nas reformas do Portugal setecentista.

Monografia de Mestrado. Rio de Janeiro: Unirio, 2011; e PASQUALE,

Daniela di. Metastasio al gusto portoghese:

Traduzioni e adattamenti del melodramma metastasiano nel Portogalo del Settecento. Roma: Aracne, 2007.

\section{Alexandre na Índia,} ópera composta em 1729, representada nas principais cidades da Europa e traduzida em português por Francisco Luiz Ameno, sob o pseudônimo de Fernando Lucas Alvim, mescla história e ficção e explora o poder do príncipe macedônico num cenário de luxo oriental que serve de pano de fundo para um drama em que se focalizam traições e amores proibidos.

\section{CONTINUAÇÃO DAS NOTAS}

59. Sobre Artaxerxes, ópera que apresenta a figura do sucessor de Xerxes I, rei da Pérsia, sabe-se que foi traduzida por Cláudio Manuel da Costa, segundo informação dada por ele em "Apontamento" apresentado à Academia Brasílica dos Renascidos, em 1759, quando de sua admissão como sócio extranumerário. Conforme o 
documento, o poeta havia traduzido o Demofoonte (que ele chama de Dircea) e o Artaxerxes, ambas com libreto de Metastasio. Informações precisas sobre o assunto podem ser obtidas em ESTEVES, S. M. P. A Ópera de Demofoonte em Trácia: tradução e adaptação de Demofoonte, de Metastasio atribuídas a Cláudio Manuel da Costa, Glauceste Satúrnio. Monografia de Mestrado. São Paulo: USP, 2007.

60. As três óperas citadas haviam sido representadas alguns anos antes em Lisboa, com música de Davide Perez, e os libretos, conforme informação de Budasz (2008, p. 71 ss.), "circulavam em versóes de cordel" com os títulos Vencer-se é o maior valor ou Alexandre nas Índias, O mais heróico segredo ou Artaxerxe e Dido desamparada ou a destruição de Cartago.

61. A Vila referida é hoje o município de Santo Amaro, a cerca de 80 quilômetros de Salvador.

62. Veja-se CALMON, Pedro. Relação das Festas que celebrou a Câmara da Vila de Nossa Senhora da Purificação, e Santo Amaro da Comarca da Bahia pelos augustíssimos desposórios da Sereníssima Senhora D. Maria princesa do Brasil com o Sereníssimo Senhor D. Pedro Infante de Portugal. Lisboa: Miguel Menescal, 1762. Apud MAGALDI [1962], p. 28.

63. Nascido no Rio de Janeiro, em 1705, de origem judaica, mas cristianizado, Antônio José mudou-se ainda na infância para Portugal onde viveu, tendo ali sido morto, vítima da Inquisição, em 1739. Embora formado em Direito, pela Universidade de Coimbra, dedicou-se às letras e escreveu sátiras e óperas cômicas, entre as quais seis com temas relacionados com a Antiguidade: Esopaida ou Vida de Esopo, obra que focaliza a figura do célebre fabulista grego; Os encantos de Medeia, ópera baseada na antiga lenda que envolve a feiticeira da Cólquida; Anfitrião ou Júpiter e Alcmena, adaptação de uma comédia plautina; Labirinto de Creta, Variedades de Proteu e Precipício de Faetonte, peças que se ocupam de conhecidos mitos helênicos. Para maiores informaçōes sobre a vida e a obra de Antônio José, veja-se: SILVEIRA, F. M. Concerto barroco às óperas do Judeu. São Paulo: Perspectiva / EDUSP, 1992

64. O drama apresenta um tom bajulatório e foi escrito, para ser representado com música, a 5 de dezembro de 1768, dia do aniversário de D. José Luís de Meneses, Conde de Valadares e Capitão-Geral da Capitania de Minas Gerais.

65. Como Cláudio Manuel da Costa, Alvarenga Peixoto também escreveu uma peça de tema clássico, Eneias no Lácio. O texto, entretanto, se perdeu e não há notícias sobre sua encenação.

66. A Casa de Ópera, atualmente Teatro Municipal de Ouro Preto, é o mais antigo teatro da América ainda em funcionamento.

67. Há notícias das representações de Ifigênia e Pirro, em 1786, e de Ipermestra, ópera de Metastasio, em 1796.

68. Coriolano em Roma, ou simplesmente Coriolano, ópera composta por Attilio Ariosti, tem

libreto de Pietro Pariati, retrabalhado por Nicola Francesco Haym. A história de Coriolano, tratada por Tito Lívio $(2,40,1)$, serviu de assunto para algumas peças teatrais a partir de Shakespeare. Cf. BRESCIA, R.; LINO, S., 2013, p. 31- 53.

69. Ezio em Roma, ou simplesmente Ezio (Aetius), é uma ópera de Metastásio que foi musicada inicialmente por Georg Friedrich Handel, estreando em Londres em 1732. Seu assunto se baseia na história romana e focaliza a rivalidade existente entre o 
Imperador Valentiniano e o general Aécio, vencedor dos hunos, ambos apaixonados pela mesma jovem. Posteriormente o libreto de Metastásio foi musicado por Nicola Porpora e por Gluck.

70. A ópera, cujo título em italiano é Alarico il Baltha, cioè l'audace re de' Gothi, tem por assunto o saque de Roma efetuado pelo general germânico.

71. Essa casa de espetáculos seria a "Ópera dos Vivos", propriedade do Pe. Ventura, que substituíra um antigo e pequeno teatro do mesmo proprietário, que funcionara anteriormente. Cf. CARDOSO, L. A. O som social. São Paulo: 2011 [A], p. 122 ss.

72. O documento referido se intitula Derrota que fez o Exmo. Sr. D. Luis Antonio de Sousa Botelho Mourão, Governador e Capitão-General da Cidade de São Paulo, indo para o Rio de Janeiro na nau de guerra

N. Sra. da Estrela. (Biblioteca Nacional, Rio de Janeiro, Divisão de Manuscritos Fundo Morgado de Mateus, 21, 4, 14, n. 1). Apud CARDOSO, 2011 [A], p. 134.

73. A ópera Demofoonte em Trácia, cujo libreto é de Metastasio, explora a história de Demofonte, rei de Atenas, que, conforme a mitologia, teria lutado na guerra de Troia e se casado com Fílis, filha de Licurgo, rei da Trácia.

74. Musicada por numerosos compositores, entre os quais Mozart, A clemência de Tito, ópera cujo assunto é uma intrincada história de amor que envolve o imperador Tito, foi objeto de numerosas representações no Brasil.

75. Em Cuiabá, onde a vida teatral foi bastante ativa desde 1731, sabemos da representação de Artaxerxe, Demofoonte em Trácia e Dido abandonada, de Metastasio, em 1786, graças a informaçōes contidas nos Anais do Senado da Câmara de Cuiabá (BUDASZ, 2008, p.193); por meio das Crônicas do Cuiabá, de José Arouche de Toledo Rendon, sabemos também de várias representações ocorridas na cidade em 1790, em honra do ouvidor Diogo de Toledo Lara Ordonhes, entre as quais estão as das óperas Ezio em Roma e Zenóbia, também de Metastásio. Cf. PÁSCOA, M. “Ópera na Amazônia durante o século XVIII”. In: Música em perspectiva. 2008 , v. 1 , n. 1 , p. $43-57$.

76. A ópera Ezio em Roma foi levada à cena em Belém, em 1793, no Theatro do Pará, inaugurado alguns anos antes. A representação foi parte das comemorações pelo nascimento de D. Maria Teresa, Princesa da Beira. Maiores informaçôes se encontram em PÁSCOA, 2008, p. 43-57.

77. Em Mazagão, no Pará, representaram-se em 1777 as óperas Demofoonte em Trácia, Dido desprezada, Eneias em Getúlia e Artaxerxes.

78. Em São Luís, em 1786, por ocasião do casamento de D. João com D. Carlota Joaquina, representou-se, como comemoração do enlace, a ópera Demofoonte.

79. Em Recife a ópera Ezio em Roma foi representada, em 1788.

80. Faculdades de Filosofia, Ciências e Letras da USP, da PUC (São Bento e Sedes Sapientiae) e da Universidade Mackenzie.

81. Para maiores informaçôes, veja-se o artigo de Ataliba Teixeira de Castilho: CASTILHO, A. T. "Robert Henri Aubreton". In: Alfa Revista de Linguística. UNESP, 1963, v. 4, p. 133-137. 
